\title{
Performance Comparison of GPFS 1.3 and GPFS 1.4 For POSIX and MPI-IO
}

Richard M. Hedges and William E. Loewe

\section{July 13, 2001}

U.S. Department of Energy

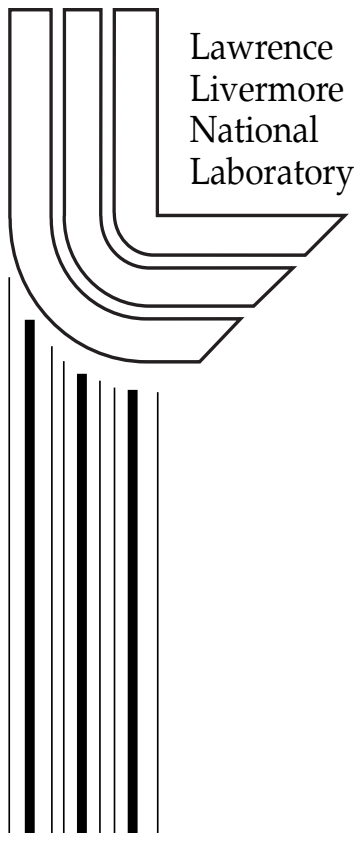




\section{DISCLAIMER}

This document was prepared as an account of work sponsored by an agency of the United States Government. Neither the United States Government nor the University of California nor any of their employees, makes any warranty, express or implied, or assumes any legal liability or responsibility for the accuracy, completeness, or usefulness of any information, apparatus, product, or process disclosed, or represents that its use would not infringe privately owned rights. Reference herein to any specific commercial product, process, or service by trade name, trademark, manufacturer, or otherwise, does not necessarily constitute or imply its endorsement, recommendation, or favoring by the United States Government or the University of California. The views and opinions of authors expressed herein do not necessarily state or reflect those of the United States Government or the University of California, and shall not be used for advertising or product endorsement purposes.

This work was performed under the auspices of the U. S. Department of Energy by the University of California, Lawrence Livermore National Laboratory under Contract No. W-7405-Eng-48.

This report has been reproduced directly from the best available copy.

Available to DOE and DOE contractors from the Office of Scientific and Technical Information

P.O. Box 62, Oak Ridge, TN 37831

Prices available from (423) 576-8401

http://apollo.osti.gov/bridge/

Available to the public from the National Technical Information Service

U.S. Department of Commerce 5285 Port Royal Rd., Springfield, VA 22161

http://www.ntis.gov/

$\mathrm{OR}$

Lawrence Livermore National Laboratory

Technical Information Department's Digital Library

http://www.llnl.gov/tid/Library.html 


\section{Performance Comparison of GPFS 1.3 and GPFS 1.4 For POSIX and MPI-IO}

This report by the SIOP observes the effects of recent hardware and software changes for parallel I/O performance to the GPFS parallel file system. The IBM SP machine (frost) has been upgraded from Mohonk with GPFS 1.3 to Mohonk2 with GPFS 1.4. In addition, the Colony switch adapters have been upgraded from Single/Single to Double/Single.

The tests discussed here were performed on frost using 60 compute nodes and the GPFS file system using 2 dedicated I/O nodes (servers).

The tests performed utilize the POSIX and MPI-IO interfaces to GPFS. The noted system changes to frost have improved both POSIX and MPI-IO peak read performance and have not diminished peak write performance. We note that as the bandwidth of mounted disks is near fully utilized, there was no expectation of significant performance improvement.

For POSIX, the best write rates did not change from $550 \mathrm{MB} / \mathrm{sec}$. The read rates improved from $500 \mathrm{MB} / \mathrm{sec}$ to $600 \mathrm{MB} / \mathrm{sec}$, however.

For MPI-IO, the best write rates did not change from $550 \mathrm{MB} / \mathrm{sec}$. The read rates improved from $470 \mathrm{MB} / \mathrm{sec}$ to $570 \mathrm{MB} / \mathrm{sec}$, in line with the improvements observed.

The MPI-IO discontiguous test results show that improvement is significant (nearly a factor of 2 beyond 40 nodes). The performance of this particular test is more sensitive to the improved switch performance characteristics because the data passes across the switch twice: once in the MPI-IO datashipping phase to assemble large block; and then to write the data out to the disks as this requires two passes across the switch. 


\section{A C H I NE C H A R A C T E R IS T I C S}

Frost, the IBM SP/6000 used for these tests, has 64 compute nodes, 2 dedicated GPFS I/O server nodes, and 1 login node.

As of May 2001, frost nodes were connected to a Colony switch by single/single adapters. This configuration on frost had the two server nodes each serving 12 logical disks through 4 cambex PC1000 fibre channel HBAs (2 each in 2 RIO drawers). The disk server system is a DataDirectNext SDD300 using a dual hstd (high speed traffic director) system with each hstd containing 4 fibre channel ports connected to the server node. The back end of the SDD (San Data Director) had 10 fibre channel loops connected to 8 data disks, 1 parity disk, and 1 spare. With 36 tiers in this system, 24 disks were created at about $860 \mathrm{~GB}$ each. The total transfer rate of these disks is approximately $700 \mathrm{MB} / \mathrm{sec}$. This hardware configuration ran the PSSP 3.2 (Mohonk) with GPFS 1.3.

In late June 2001, frost was upgraded to double/single switch adapters and PSSP 3.3 (Mohonk2) with GPFS 1.4. Except for the new adapters, this hardware configuration of frost is the same as the earlier configuration.

\section{TEST S \& R E S U T S}

A maximum of 60 compute nodes were used due to a few nodes being unavailable during test times. The parallel codes ior_posix.c and ior_mpiio.c were used for various access patterns for POSIX and MPI-IO. For discontiguous testing under MPI-IO, mpiio_discontig.c was used.

Three general data layout patterns have been used: 1) a segmented pattern, where all data from a single process will be written to a contiguous portion of the file; 2 ) strided, where data from the processes is interleaved in the file, and 3) discontiguous, where the file is divided into $1 \mathrm{k}$ blocks, which are then randomly assigned to the processes.

\section{P O S I X}

The first round of testing using GPFS 1.3 used the POSIX interface with strided and segmented access patterns, varying the node count and transfer size. The comparable tests were performed on GPFS 1.4.

The hardware/software changes in moving from GPFS 1.3 to GPFS 1.4 has lead to improvement in the POSIX read performance and has not diminished write performance. As the disks were already saturated, there was not an expectation of performance improvement beyond $700 \mathrm{MB} / \mathrm{sec}$.

So, despite read rates increasing, it was no surprise that write rates have not changed. For POSIX, the best write rates did not change from $550 \mathrm{MB} / \mathrm{sec}$. 


\section{Segmented}

Testing for scalability with a segmented pattern, test 1.4 is as follows:

Clients/Node: 1 Filesize: .5GB - 30GB Code: ior_posix.c May: GPFS 1.3

Nodes: 1 - 60 Transfersize: 512KB Machine: frost.llnl.gov June: GPFS: 1.4

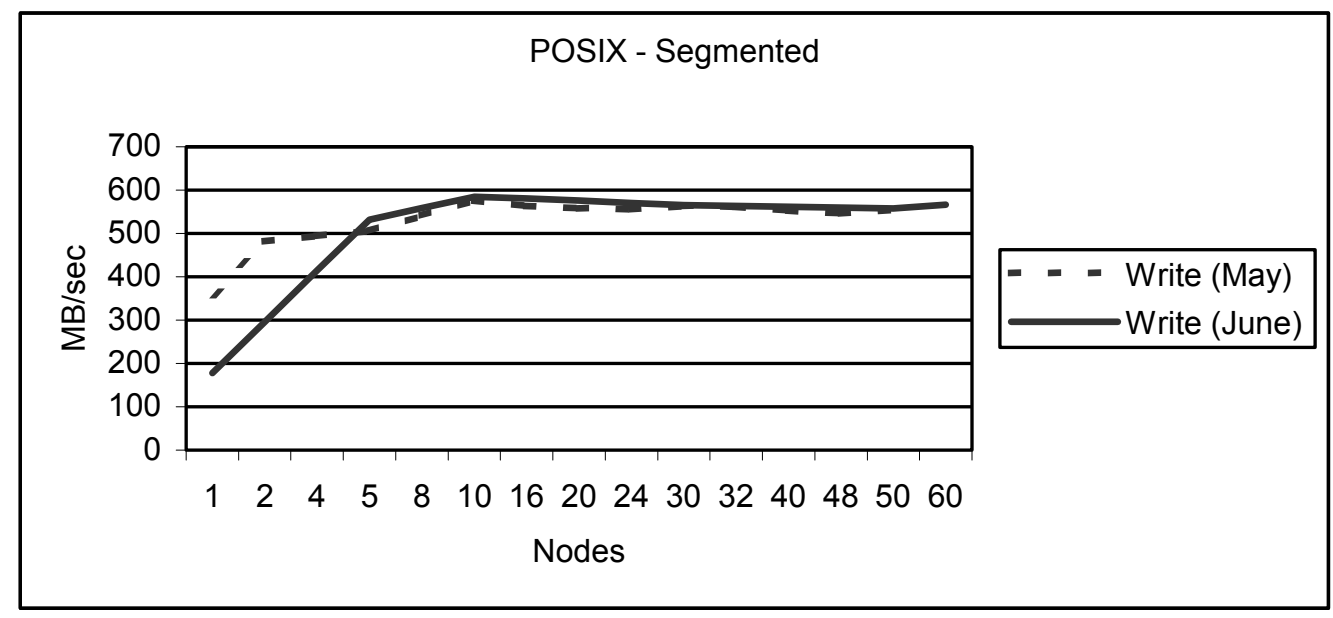

The read rates improved from $500 \mathrm{MB} / \mathrm{sec}$ to $600 \mathrm{MB} / \mathrm{sec}$, from GPFS 1.3 to GPFS 1.4.

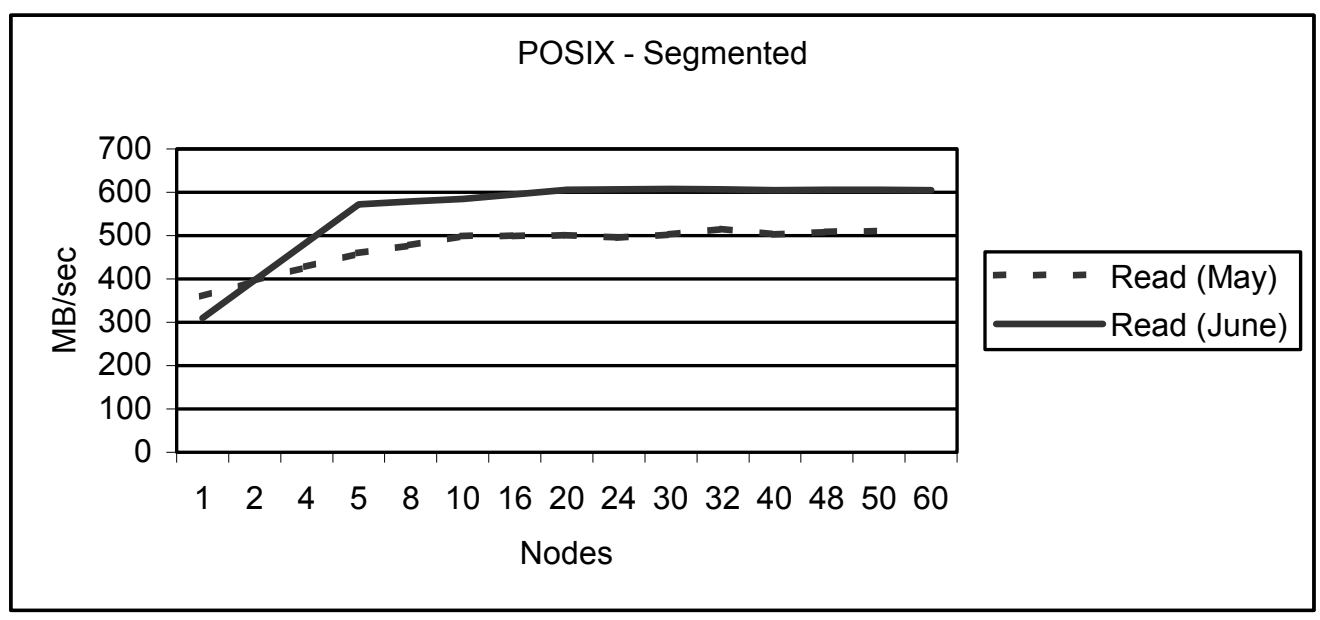




\section{Strided}

For writes to a strided access pattern, the performance increased nearly $100 \mathrm{MB} / \mathrm{sec}$ for all stride sizes.

$\begin{array}{cccc}\text { Clients/Node: } 1 & \text { Filesize: } 30 \mathrm{~GB} & \text { Code: ior_posix.c } & \text { May: GPFS } 1.3 \\ \text { Nodes: } 60 & \text { Stridesize: .5MB-16MB } & \text { Machine: frost.llnl.gov } & \text { June: GPFS: } 1.4\end{array}$

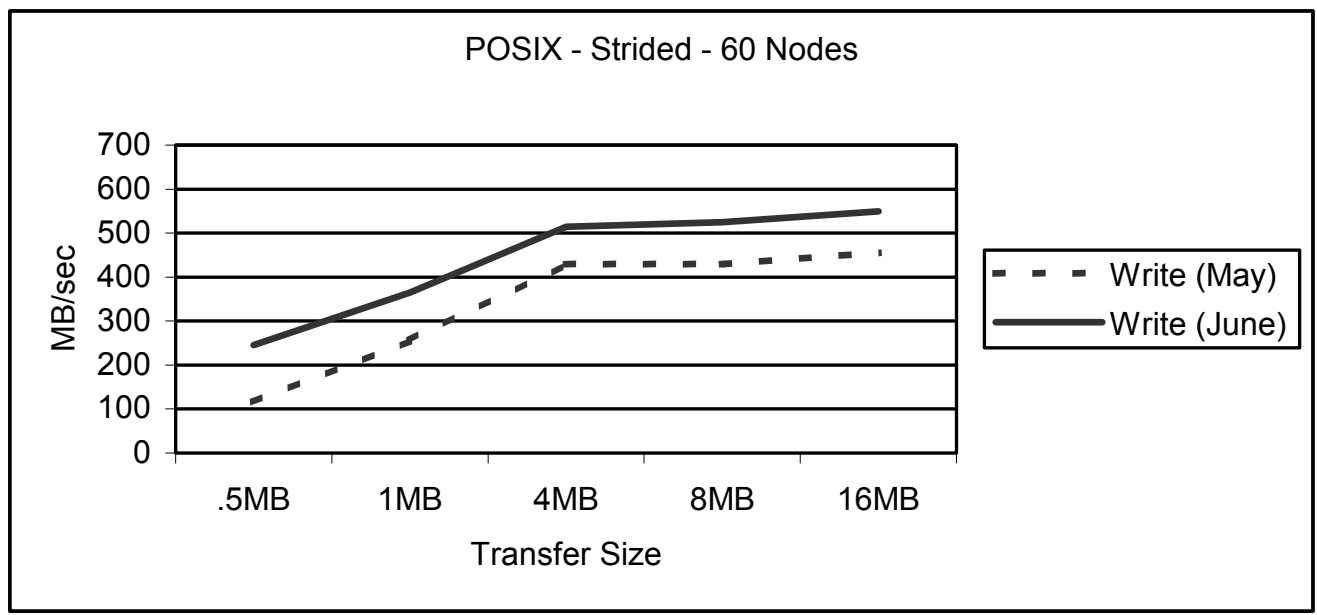

For reads from a strided access pattern, the performance increased by approximately 100 $\mathrm{MB} / \mathrm{sec}$ for all stride sizes.

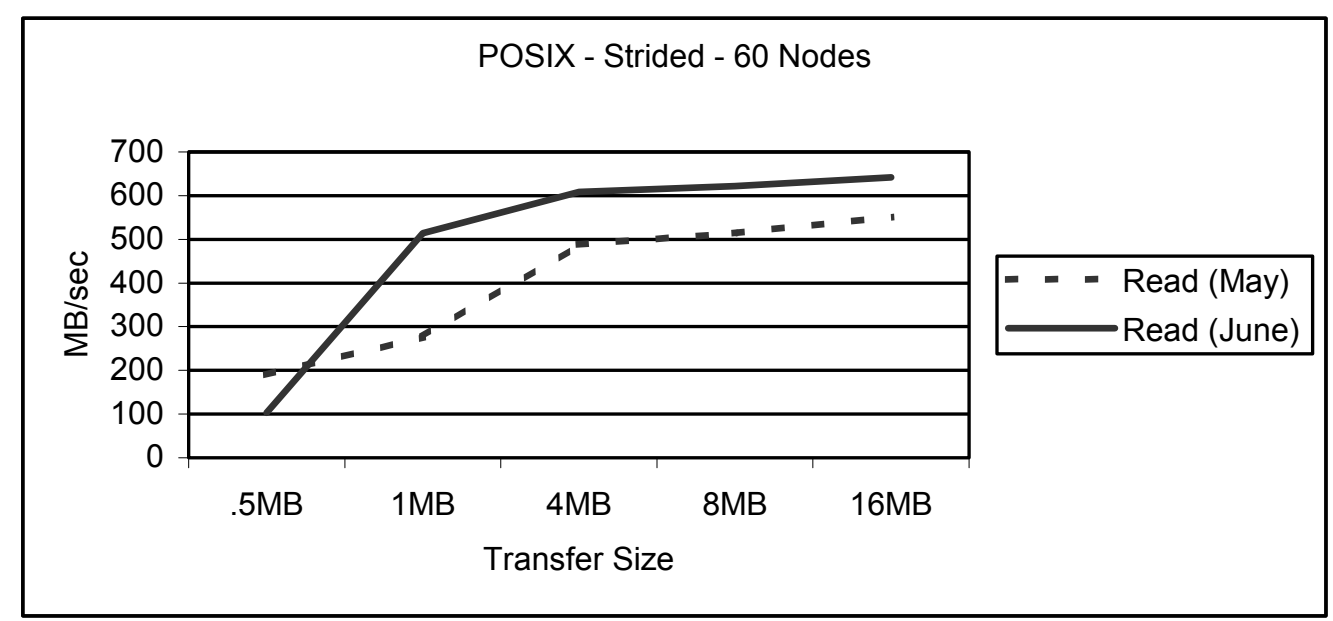

Further, it is interesting to note that for the strided pattern in test 1.1 with transfersize set to $16 \mathrm{MB}$, the maximum read is $549 \mathrm{MB} / \mathrm{sec}$ on GPFS 1.3 . Though with only 3 repetitions of each test, it appears that this is nearly $7 \%$ faster than any of the segmented 1.4 tests for read. The same is true on GPFS 1.4 for the strided pattern in test 1.1 with transfersize set to $16 \mathrm{MB}$. This read rate of $642 \mathrm{MB} / \mathrm{sec}$, too, is better than any of the segmented tests on GPFS 1.4 by nearly $6 \%$. 


\section{P I - I O}

The MPI-IO read performance, too, has improved and the write performance has maintained the maximum write rate set by the disks.

For MPI-IO, the best write rates did not change from $550 \mathrm{MB} / \mathrm{sec}$. The read rates improved from $470 \mathrm{MB} / \mathrm{sec}$ to $570 \mathrm{MB} / \mathrm{sec}$.

\section{Discontiguous}

$\begin{array}{cccc}\text { Clients/Node: } 1 & \text { Filesize: 30GB } & \text { Code: mpiio_discontig.c } & \text { May: GPFS } 1.3 \\ \text { Nodes: 2-60 } & \text { Blocksize: } 1 \mathrm{~KB} & \text { Machine: frost.Inl.gov } & \text { June: GPFS: } 1.4\end{array}$

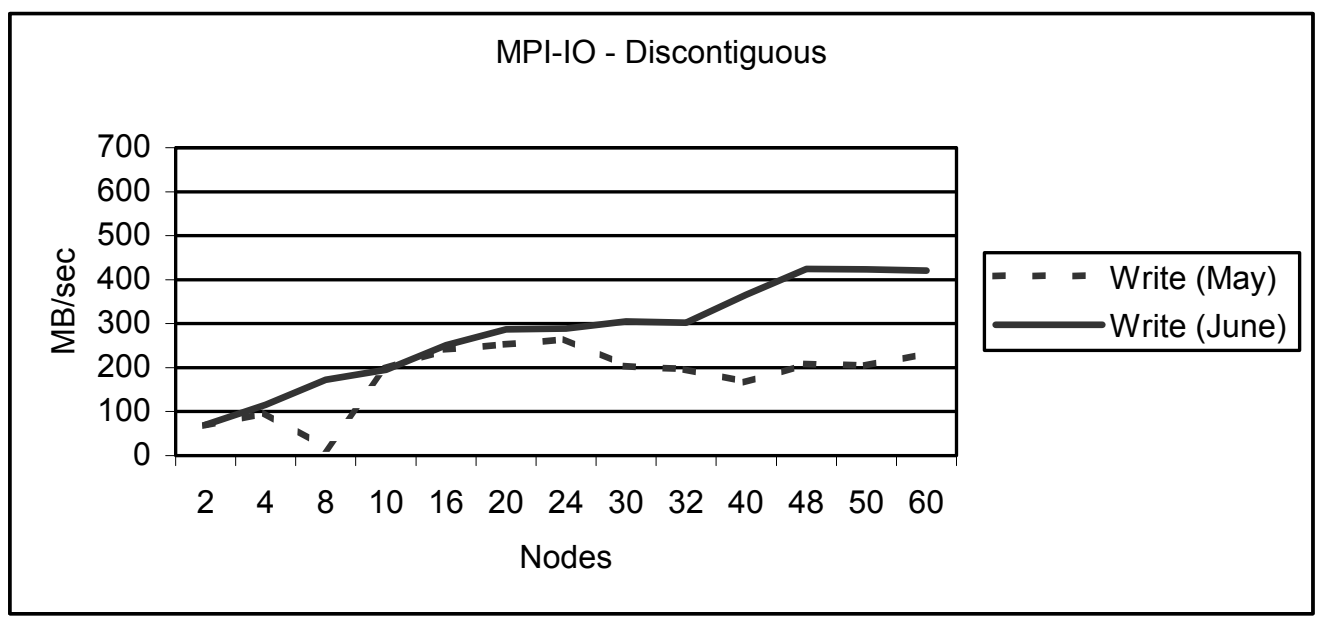

The MPI-IO Discontiguous test results show that the improvement for data shipping is significant (nearly a factor of 2 beyond 40 nodes). It is noteworthy as this write pattern requires two passes across the switch. This suggests that with reducing the bottleneck at the disks, there might be an improvement in performance since the switch could handle more traffic faster. 


\section{Segmented}

Clients/Node: 1

Nodes: 1-60
Filesize: $30 \mathrm{~GB}$

Transfersize: 512KB
Code: ior_mpiio.c

Machine: frost.IInl.gov
May: GPFS 1.3

June: GPFS: 1.4
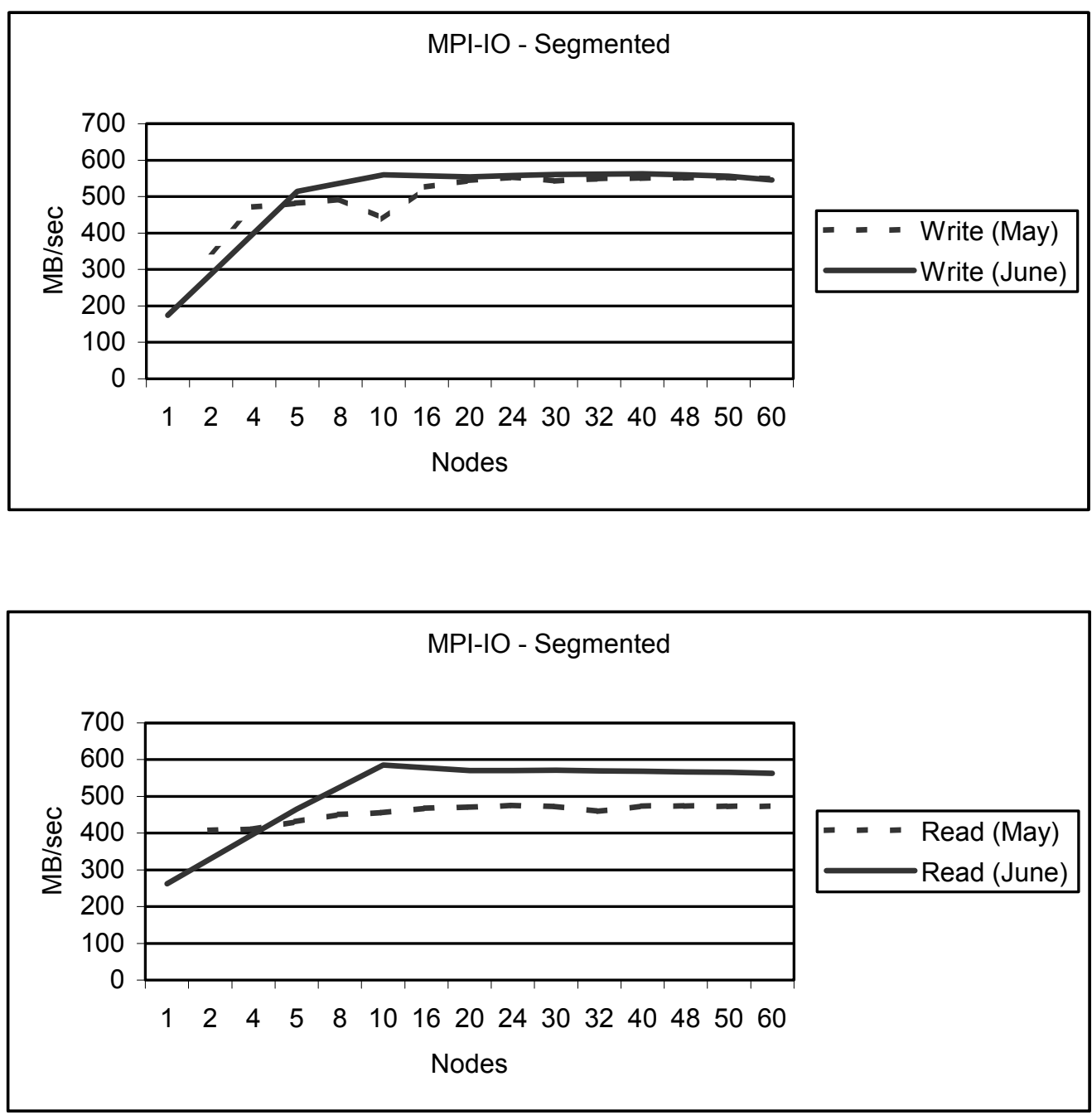


\section{O U T P U T D A A}

Test: Clients/Node: 1 Filesize: 30GB Code: ior_posix.c May: GPFS 1.3

1.1 Nodes: 60 Transfersize: .5-16MB Machine: frost.IInl.gov June: GPFS: 1.4

\begin{tabular}{|c|c|c|c|c|}
\hline Interface & Pattern & File size & Nodes & Reps \\
\hline POSIX & Strided & $30 G$ & 60 & 3 \\
\hline \multicolumn{5}{|c|}{ [Note: All Rates in MB/sec } \\
\hline Block size & Transfer size & 29-May & Write & Read \\
\hline $.5 \mathrm{MB}$ & $.5 \mathrm{MB}$ & & 116 & 245 \\
\hline $1 \mathrm{MB}$ & $1 \mathrm{MB}$ & & 256 & 365 \\
\hline $4 \mathrm{MB}$ & $4 \mathrm{MB}$ & & 429 & 514 \\
\hline $8 \mathrm{MB}$ & $8 \mathrm{MB}$ & & 429 & 525 \\
\hline \multirow[t]{2}{*}{$16 \mathrm{MB}$} & $16 \mathrm{MB}$ & & 456 & 549 \\
\hline & & 28-Jun & Write & Read \\
\hline $.5 \mathrm{MB}$ & $.5 \mathrm{MB}$ & & 190 & 103 \\
\hline $1 \mathrm{MB}$ & $1 \mathrm{MB}$ & & 277 & 514 \\
\hline $4 \mathrm{MB}$ & $4 \mathrm{MB}$ & & 488 & 608 \\
\hline $8 \mathrm{MB}$ & $8 \mathrm{MB}$ & & 514 & 622 \\
\hline $16 \mathrm{MB}$ & $16 \mathrm{MB}$ & & 551 & 642 \\
\hline
\end{tabular}

Test: Clients/Node: 1 File size: 30GB Code: ior_posix.c May: GPFS 1.3

1.4 Nodes: 60 Transfer size: 512KB Machine: frost.llnl.gov June: GPFS: 1.4

\begin{tabular}{cccc}
$\begin{array}{c}\text { Interface } \\
\text { POSIX }\end{array}$ & $\begin{array}{c}\text { Pattern } \\
\text { Segmented }\end{array}$ & $\begin{array}{c}\text { Transfer size } \\
\text { 512KB }\end{array}$ & \multicolumn{2}{c}{$\begin{array}{c}\text { Rodes } \\
\text { [Note: All Rates in MB/sec] }\end{array}$} \\
& & \multicolumn{2}{c}{ Reps } \\
Nodes & 29-May & Write & Read \\
2 & 359 & 360 \\
4 & 482 & 395 \\
8 & 506 & 460 \\
10 & 541 & 478 \\
16 & 576 & 499 \\
20 & 563 & 499 \\
24 & 558 & 501 \\
30 & 556 & 495 \\
32 & 563 & 503 \\
40 & 562 & 515 \\
48 & 553 & 503 \\
50 & 546 & 509 \\
60 & 555 & 510
\end{tabular}


Test: 1.4 (cont.)

1
5
10
20
30
40
50
60

Test: Clients/Node: 1

2.1 Nodes: 2-60

$\begin{array}{cc}\begin{array}{c}\text { Interface } \\ \text { MPI-IO }\end{array} & \begin{array}{c}\text { Pattern } \\ \text { Discontiguous }\end{array} \\ \begin{array}{c}\text { File size } \\ 1 G B\end{array} & \begin{array}{c}\text { Nodes } \\ 2 G B\end{array} \\ 2 \\ 4 G B & 4 \\ 5 G B & 8 \\ 8 G B & 10 \\ 10 G B & 16 \\ 12 G B & 20 \\ 15 G B & 24 \\ 16 G B & 30 \\ 20 G B & 32 \\ 24 G B & 40 \\ 25 G B & 48 \\ 30 G B & 50 \\ \end{array}$

$\begin{array}{ccc}\text { 28-Jun } & \text { Write } & \text { Read } \\ 178 & 310 \\ 532 & 572 \\ 585 & 585 \\ 576 & 606 \\ 565 & 608 \\ 562 & 605 \\ 558 & 606 \\ 566 & 605\end{array}$

\begin{tabular}{|c|c|c|c|c|}
\hline $\begin{array}{l}\text { File size: } 30 \mathrm{~GB} \\
\text { Block size: } 1 \mathrm{~KB}\end{array}$ & \multicolumn{2}{|c|}{$\begin{array}{l}\text { Code: mpiio_discontig.c } \\
\text { Machine: frost.IInl.gov }\end{array}$} & \multicolumn{2}{|c|}{$\begin{array}{l}\text { May: GPFS } 1.3 \\
\text { June: GPFS: } 1.4\end{array}$} \\
\hline $\begin{array}{c}\text { Pattern } \\
\text { Discontiguous }\end{array}$ & \multicolumn{4}{|c|}{$\begin{array}{lc}5 & 1 \mathrm{~KB} \\
{[\text { Note: }} & \text { All Rates in MB/sec] }\end{array}$} \\
\hline Nodes & 29-May & Write & 28-Jun & Write \\
\hline 2 & & 68 & & 70 \\
\hline 4 & & 98 & & 116 \\
\hline 8 & & 17 & & 172 \\
\hline 10 & & 198 & & 195 \\
\hline 16 & & 242 & & 251 \\
\hline 20 & & 253 & & 287 \\
\hline 24 & & 264 & & 289 \\
\hline 30 & & 204 & & 305 \\
\hline 32 & & 196 & & 302 \\
\hline 40 & & 167 & & 366 \\
\hline 48 & & 208 & & 424 \\
\hline 50 & & 205 & & 423 \\
\hline 60 & & 232 & & 421 \\
\hline
\end{tabular}


Test: Clients/Node: 1 File size: 30GB Code: ior_posix.c May: GPFS 1.3

2.3 Nodes: 60 Transfer size: .5-16MB Machine: snow.llnl.gov June: GPFS: 1.4

\begin{tabular}{|c|c|c|c|}
\hline \multirow{3}{*}{$\begin{array}{c}\text { Interface } \\
\text { MPI-IO }\end{array}$} & \multirow{3}{*}{$\begin{array}{c}\text { Pattern } \\
\text { Segmented }\end{array}$} & Transfer size & Reps \\
\hline & & $512 \mathrm{~KB}$ & 3 \\
\hline & & \multicolumn{2}{|c|}{ [Note: All Rates in MB/sec] } \\
\hline Nodes & 29-May & Write (MB/sec) & $\operatorname{Read}(\mathrm{MB} / \mathrm{sec})$ \\
\hline 2 & & 350 & 408 \\
\hline 4 & & 472 & 411 \\
\hline 8 & & 493 & 451 \\
\hline 10 & & 439 & 456 \\
\hline 16 & & 527 & 468 \\
\hline 20 & & 545 & 471 \\
\hline 24 & & 553 & 475 \\
\hline 30 & & 543 & 473 \\
\hline 32 & & 549 & 459 \\
\hline 40 & & 550 & 474 \\
\hline 48 & & 551 & 474 \\
\hline 50 & & 552 & 473 \\
\hline \multirow[t]{2}{*}{60} & & 549 & 473 \\
\hline & 28-Jun & Write & Read \\
\hline 1 & & 174 & 262 \\
\hline 5 & & 514 & 465 \\
\hline 10 & & 560 & 585 \\
\hline 20 & & 554 & 570 \\
\hline 30 & & 561 & 571 \\
\hline 40 & & 563 & 568 \\
\hline 50 & & 556 & 566 \\
\hline 60 & & 546 & 563 \\
\hline
\end{tabular}

